\title{
Analisa dan Perbandingan PLTS on Grid yang Terpasang di Atap Gedung Utama PT Subur Semesta dengan PLTS On Grid yang Bergerak Mengikuti Arah Matahari
}

\author{
Deni Almanda ${ }^{1}$, Moh. Akhsin Zaenal Muttaqin ${ }^{2}$ \\ 1) 2) Teknik Elektro Universitas Muhammadiyah Jakarta \\ Jl. Cempaka Putih Tengah 27 \\ Email: ${ }^{1)}$ deni.almanda@ftumj.ac.id , 2) 2012420055@ftumj.ac.id
}

\begin{abstract}
ABSTRAK
Berdasarkan Permasalahan kebutuhan listrik di kalangan industri maka energi surya di pilih sebagai salah satu energi alternatif untuk menghasilkan energi listrik. Energi surya yang di hasilkan di siang hari bisa membuat penghematan daya berdasarkan cara pemasangan modul surya, pemakaian inverter yang sesuai dan instalasi standar yang terpasang. Pemasangan modul surya di atap gedung dengan pemasangan yang mengikuti arah matahari sangat berpengaruh pada energi listrik yang di hasilkan maka dari itu memaksimalkan keluaran listrik dari modul surya sangat di perlukan.
\end{abstract}

Kata kunci : Modul surya, GTI, PV Analyzer

ABSTRACT

Based on the problem of electricity demand in the industry, solar energy is chosen as an alternative energy to produce electrical energy. Solar energy generated during the day can make power savings based on how to install solar modules, the use of an appropriate inverter and the installed standard installation. Installation of solar modules on the roof of the building with the installation that follows the direction of the sun is very influential on the electrical energy generated and therefore maximizing the electrical output of the solar module is needed.

Keywords: Solar Module, GTI, PV Analyzer

\section{PENDAHULUAN}

Energi matahari adalah salah satu energi terbarukan utama [1]. Pemanfaatan energi ini sangat penting di mana-mana [2]. Fotovoltaik adalah teknologi dan penelitian yang berhubungan dengan aplikasi panel surya [3]. Indonesia adalah negara tropis yang letak geografisnya dilalui oleh garis khatulistiwa sehingga mempunyai potensi energi panas matahari yang cukup besar Berdasarkan Permasalahan kebutuhan listrik di kalangan industri maka energi surya di pilih sebagai salah satu energi alternatif untuk menghasilkan energi listrik energi surya yang di hasilkan di siang hari bisa membuat Penghematan daya berdasarkan cara pemasangan modul surya, pemakaian inverter yang sesuai dan instalasi standar yang terpasang Pemasangan modul surya di atap gedung dengan pemasangan yang mengikuti arah matahari sangat berpengaruh pada energi listrik yang di hasilkan maka dari itu memaksimalkan keluaran listrik dari modul surya sangat di perlukan. Penelitian ini bertujuan untuk mengetahui dan menganalisa hasil energi listrik yang lebih maksimal dari pemasangan di atap gedung dengan pemasangan yang mengikuti arah gerak matahari kemudian di konversikan dengan biaya penghasilan dari tiap tiap pemasangan tersebut.

\section{METODOLOGI}

Pengambilan data PLTS on Grid yang terpasang di atap gedung dilakukan untuk mengetahui energi listrik yang dihasilkan. Adapun Langkahlangkah pengambilan data ditunjukan oleh flowchart di bawah ini :

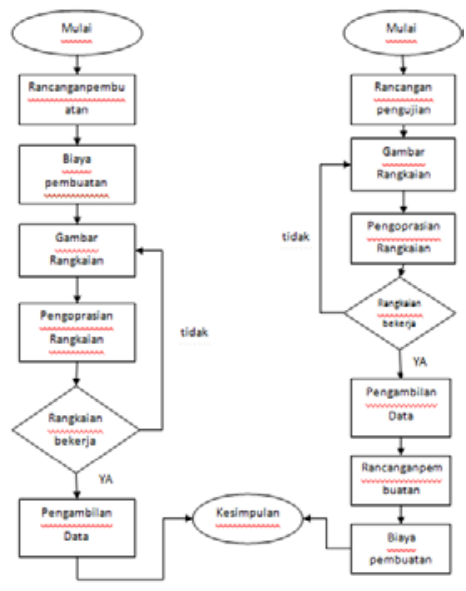

Gambar 1 Diagram alir. 
RESISTOR (Elektronika Kendali Telekomunikasi Tenaga Listrik Komputer) Vol. 3 No. 2 e-ISSN : 2621-9700, p-ISSN : 2654-2684

Kemudian hasil dari pengambilan data PLTS on Grid yang sudah terpasang di atap gedung dibandingkan dengan hasil pengukuran penelitian PLTS on Grid yang mengikuti arah matahari. Dari kedua hasil tersebut akan di ketahui lebih maksimal mana energi yang di hasilkan oleh PLTS.

\section{HASIL DAN PEMBAHASAN}

Adapun gambar dan design PLTS on grid yang sudah terpasang di PT Subur Semesta seperti di bawah ini.

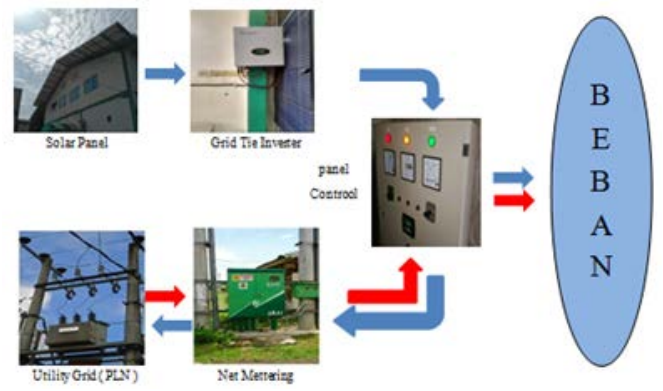

Gambar 2 Gambar design PLTS on grid.

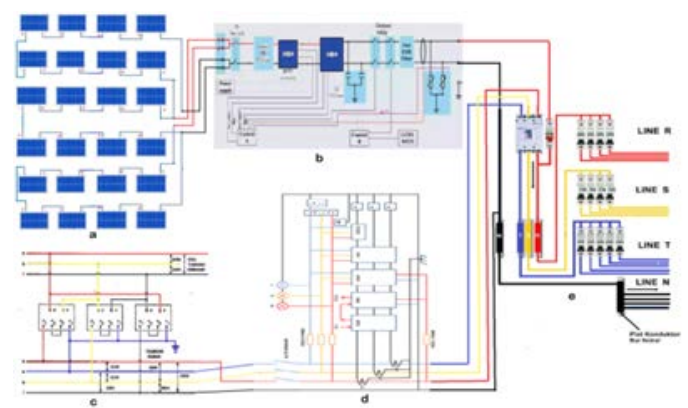

Gambar 3 Gambar Rangkaian PLTS on grid.

Harga biaya pembuatan PLTS on grid yang sudah terpasang di dapat dengan mencari langsung pemasok yang menjual. Berikut tabel investasi PLTS on grid yang sudah terpasang.

Tabel 1 Investasi PLTS on grid.

\begin{tabular}{|c|c|c|c|c|c|}
\hline & QYT & Satuan & \multicolumn{2}{|c|}{ Harga } & Total \\
\hline Panel surya 300 wp & 24 & pcs & 7.000 .000 & pes & 168.000 .000 \\
\hline On grid inverter $10 \mathrm{kw}$ & 1 & Pcs & 25.000 .000 & pcs & 25.000 .000 \\
\hline KonektorMC4 & 48 & pcs & 25.000 & pcs & 1.200 .000 \\
\hline Konektor MC4Y & 11 & pes & 40.000 & pcs & 440.000 \\
\hline Kabel $2 \times 4 \mathrm{~mm}^{2}$ & 300 & meter & 450.000 & $150 \mathrm{~m}$ & 2.700 .000 \\
\hline Besi siku $50 \times 50 \times 40 \mathrm{~mm}$ & 90 & meter & 150.000 & $16 \mathrm{~m}$ & 2.250 .000 \\
\hline Baut M8x $60 \mathrm{~mm}$ & 300 & pcs & 2000 & pcs & 600.000 \\
\hline MurM8 & 350 & pes & 1000 & pcs & 350.000 \\
\hline $\mathrm{MCB} 40 \mathrm{~A}$ & 1 & pcs & 150.000 & /1 pcs & 150.000 \\
\hline Klem kabel $2 \times 4 \mathrm{~mm}^{2}$ & 500 & pcs & 5000 & $/ 50 \mathrm{pcs}$ & 250.000 \\
\hline Rel tembaga $500 \times 30 \times 4$ & 5 & pcs & 195.000 & $/ 1 \mathrm{pcs}$ & 975.000 \\
\hline isolator rel tembaga & 10 & pcs & 15.000 & /1 pcs & 150.000 \\
\hline Baut M8x $30 \mathrm{~mm}$ & 50 & pes & 1500 & /1 pcs & 75.000 \\
\hline $\begin{array}{l}\text { Biaya pemasangan, } \\
\text { pengerja an rangka dan } \\
\text { instalasi PLTS }\end{array}$ & 10 & Kw & 2.500 .000 & $/ \mathrm{kw}$ & 25.000 .000 \\
\hline Total & & & & & 227.140 .000 \\
\hline
\end{tabular}

Biaya pemeliharaan dan operasional ( $\mathrm{M}$ ) per tahun untuk PLTS on grid yang sudah terpasang adalah sebagai berikut:

$$
\begin{aligned}
& M=1 \% \times \text { Total Biaya Investasi } \\
& M=1 \% \text { x } 227.140 .000 \\
& M=\text { Rp 2.271.400 Per Tahun }
\end{aligned}
$$

maka total biaya pemeliharaan dan operasional untuk 20 tahun adalah sebesar Rp 45.428.000

Total investasi adalah total biaya yang di perkirakan mencakup total biaya investasi awal dan biaya pemeliharaan selama 20 tahun maka:

Total Investasi $=\mathrm{Rp} 227.140 .000+\mathrm{Rp}$ 45.428.000

\begin{tabular}{|c|c|c|c|c|c|c|}
\hline & \multicolumn{2}{|c|}{ Harike 1} & \multicolumn{2}{|c|}{ Hari ke? } & \multicolumn{2}{|c|}{ Harike 3} \\
\hline $\mathrm{Jam}$ & Radasis matahari & \begin{tabular}{|l} 
Listrik yang \\
d. hasilkan
\end{tabular} & \begin{tabular}{|l|l|} 
Radäasi \\
matatari
\end{tabular} & $\begin{array}{l}\text { Listrik yang } \\
\text { di hasilkan }\end{array}$ & \begin{tabular}{|l} 
Radiasi \\
matathari
\end{tabular} & $\begin{array}{l}\text { Listrik yang } \\
\text { d hasilkan }\end{array}$ \\
\hline 09.00 & 470 & 8.8 & 440 & 7,5 & 445 & 8,5 \\
\hline 10.00 & 560 & 109 & 510 & 8.9 & 515 & 9,9 \\
\hline 11.00 & 690 & 14,8 & 650 & 13,8 & 654 & 14.8 \\
\hline 12.00 & 830 & 21,8 & 820 & 20,8 & 836 & 22,8 \\
\hline 13.00 & 750 & 17,7 & 720 & 15,7 & 725 & 16,5 \\
\hline 14.00 & 710 & 16,4 & 700 & 14,4 & 718 & 15,4 \\
\hline 15.00 & 590 & 13,5 & 550 & 10,5 & 595 & 13,5 \\
\hline 16.00 & 420 & 72 & 390 & 6.2 & 425 & 72 \\
\hline Total & 5.020 & $110 \mathrm{krth}$ & 4.780 & $97.8 \mathrm{krth}$ & 4.913 & 108kxin | \\
\hline
\end{tabular}

Total Investasi $=$ Rp 272.568.000

Tabel 2 Energi yang di hasilkan. 
RESISTOR (Elektronika Kendali Telekomunikasi Tenaga Listrik Komputer) Vol. 3 No. 2 e-ISSN : 2621-9700, p-ISSN : 2654-2684

\begin{tabular}{|c|c|c|c|c|c|c|}
\hline & \multicolumn{2}{|c|}{ Hari ke 4} & \multicolumn{2}{|c|}{ Hari ke 5} & \multicolumn{2}{|c|}{ Hari ke 6} \\
\hline Jam & $I_{\text {matahari }}^{\text {Radiasi }}$ & $\begin{array}{l}\text { Daya yang } \\
\text { d hasilkan }\end{array}$ & $\begin{array}{l}\text { Radiasi } \\
\text { matahari }\end{array}$ & $\begin{array}{l}\text { Daya yang } \\
\text { di hasilkan }\end{array}$ & $\begin{array}{l}\text { Radiasi } \\
\text { matahari }\end{array}$ & $\begin{array}{l}\text { Daya yang } \\
\text { di hasilkan }\end{array}$ \\
\hline 09.00 & 410 & 7,1 & 490 & 8,5 & 440 & 7,5 \\
\hline 10.00 & 500 & 08.02 & 580 & 10,9 & 510 & 8,9 \\
\hline 11.00 & 650 & 13,8 & 700 & 14,1 & 650 & 13,8 \\
\hline 12.00 & 800 & 19,3 & 880 & 22,6 & 720 & 15,5 \\
\hline 13.00 & 710 & 14,3 & 820 & 20,7 & 820 & 20,7 \\
\hline 14.00 & 690 & 13,4 & 760 & 17,4 & 700 & 14,4 \\
\hline 15.00 & 550 & 10,5 & 530 & 10,1 & 550 & 10,5 \\
\hline 16.00 & 300 & 5,2 & 430 & 7,4 & 390 & 6,2 \\
\hline Total & 4.610 & $91.8 \mathrm{kvh}$ & 4.780 & $111.7 \mathrm{kuh}$ & 4.780 & $97.8 \mathrm{krh}$ \\
\hline
\end{tabular}

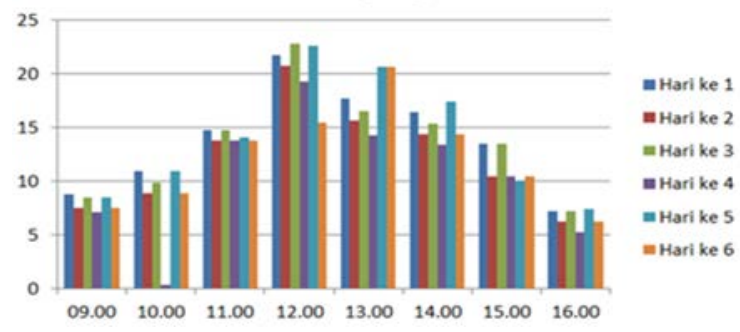

Gambar 4 .

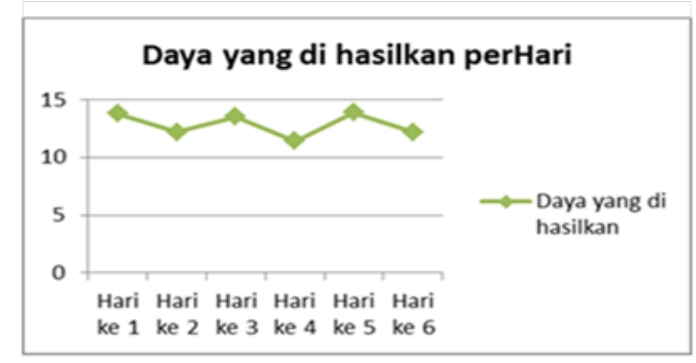

Gambar 5 .

Hasil rata rata energi yang di hasilkan setiap minggu adalah 80,75 Kwh.

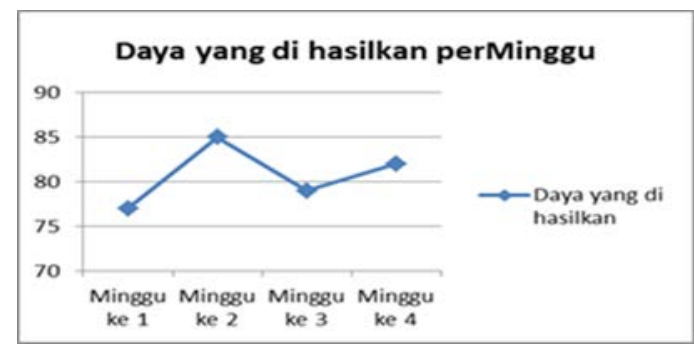

Gambar 6 . 
RESISTOR (Elektronika Kendali Telekomunikasi Tenaga Listrik Komputer) Vol. 3 No. 2 e-ISSN : 2621-9700, p-ISSN : 2654-2684

\begin{tabular}{|l|r|r|r|}
\hline & \multicolumn{3}{|c|}{ Hari ke 3 } \\
\hline Jam & $\begin{array}{l}\text { Radiasi } \\
\text { matahan }\end{array}$ & $\begin{array}{l}\text { Panas } \\
\text { modul } \\
\text { Surya }\end{array}$ & $\begin{array}{l}\text { Daya } \\
\text { yang di } \\
\text { hasilkan }\end{array}$ \\
\hline 09.00 & 440 & $22^{\circ} \mathrm{c}$ & $640 \mathrm{wh}$ \\
\hline 10.00 & 510 & $30^{\circ} \mathrm{c}$ & $690 \mathrm{wh}$ \\
\hline 11.00 & 650 & $39^{\circ} \mathrm{c}$ & $850 \mathrm{wh}$ \\
\hline 12.00 & 720 & $44^{\circ} \mathrm{c}$ & $1050 \mathrm{wh}$ \\
\hline 13.00 & 820 & $52^{\circ} \mathrm{c}$ & $1230 \mathrm{wh}$ \\
\hline 14.00 & 700 & $41^{\circ} \mathrm{c}$ & $870 \mathrm{wh}$ \\
\hline 15.00 & 550 & $35^{\circ} \mathrm{c}$ & $800 \mathrm{wh}$ \\
\hline 16.00 & 390 & $20^{\circ} \mathrm{c}$ & $550 \mathrm{wh}$ \\
\hline Total & 4.780 & $282.4^{\circ} \mathrm{c}$ & $6680 \mathrm{wh}$ \\
\hline Rata-rata & 597.5 & $35.3^{\circ} \mathrm{c}$ & $835 \mathrm{wh}$ \\
\hline
\end{tabular}

\begin{tabular}{r|r|r|}
\hline \multicolumn{3}{|c|}{ Hari ke 4} \\
\hline $\begin{array}{l}\text { Radiasi } \\
\text { matahari }\end{array}$ & $\begin{array}{l}\text { Panas } \\
\text { modul } \\
\text { surya }\end{array}$ & $\begin{array}{l}\text { Daya } \\
\text { yang di } \\
\text { hasilkan }\end{array}$ \\
\hline 390 & $19^{\circ} \mathrm{c}$ & $550 \mathrm{wh}$ \\
\hline 480 & $27^{\circ} \mathrm{c}$ & $670 \mathrm{wh}$ \\
\hline 630 & $37^{\circ} \mathrm{c}$ & $830 \mathrm{wh}$ \\
\hline 790 & $47^{\circ} \mathrm{c}$ & $1150 \mathrm{wh}$ \\
\hline 710 & $42^{\circ} \mathrm{c}$ & $1000 \mathrm{wh}$ \\
\hline 690 & $40^{\circ} \mathrm{c}$ & $950 \mathrm{wh}$ \\
\hline 520 & $33^{\circ} \mathrm{c}$ & $754 \mathrm{wh}$ \\
\hline 350 & $17^{\circ} \mathrm{c}$ & $470 \mathrm{wh}$ \\
\hline 4.560 & $262^{\circ} \mathrm{c}$ & $6374 \mathrm{wh}$ \\
\hline 570 & $32,7^{\circ} \mathrm{c}$ & $796,7 \mathrm{wh}$ \\
\hline
\end{tabular}

\begin{tabular}{|l|r|r|r|r|r|r|}
\hline & \multicolumn{3}{|c|}{ Hari ke 5 } & \multicolumn{3}{c|}{ Hari ke 6 } \\
\hline Jam & $\begin{array}{l}\text { Radiasi } \\
\text { matahan }\end{array}$ & $\begin{array}{l}\text { Panas } \\
\text { modul } \\
\text { Surya }\end{array}$ & $\begin{array}{l}\text { Daya } \\
\text { yang di } \\
\text { hasilkan }\end{array}$ & $\begin{array}{l}\text { Radiasi } \\
\text { matahan }\end{array}$ & $\begin{array}{l}\text { Panas } \\
\text { modul } \\
\text { Surya }\end{array}$ & $\begin{array}{l}\text { Daya } \\
\text { yang di } \\
\text { hasilkan }\end{array}$ \\
\hline 09.00 & 490 & $28^{\circ} \mathrm{c}$ & $680 \mathrm{wh}$ & 420 & $21^{\circ} \mathrm{c}$ & $630 \mathrm{wh}$ \\
\hline 10.00 & 610 & $35^{\circ} \mathrm{c}$ & $800 \mathrm{wh}$ & 490 & $28^{\circ} \mathrm{c}$ & $680 \mathrm{wh}$ \\
\hline 11.00 & 790 & $47^{\circ} \mathrm{c}$ & $1150 \mathrm{wh}$ & 630 & $37^{\circ} \mathrm{c}$ & $830 \mathrm{wh}$ \\
\hline 12.00 & 900 & $57^{\circ} \mathrm{c}$ & $1400 \mathrm{wh}$ & 800 & $49^{\circ} \mathrm{c}$ & $1200 \mathrm{wh}$ \\
\hline 13.00 & 820 & $51^{\circ} \mathrm{c}$ & $1230 \mathrm{wh}$ & 700 & $41^{\circ} \mathrm{c}$ & $990 \mathrm{wh}$ \\
\hline 14.00 & 740 & $45^{\circ} \mathrm{c}$ & $1100 \mathrm{wh}$ & 680 & $40^{\circ} \mathrm{c}$ & $950 \mathrm{wh}$ \\
\hline 15.00 & 530 & $33^{\circ} \mathrm{c}$ & $760 \mathrm{wh}$ & 530 & $31^{\circ} \mathrm{c}$ & $769 \mathrm{wh}$ \\
\hline 16.00 & 430 & $22^{\circ} \mathrm{c}$ & $640 \mathrm{wh}$ & 370 & $18^{\circ} \mathrm{c}$ & $490 \mathrm{wh}$ \\
\hline Total & 5310 & $318^{\circ} \mathrm{c}$ & $7760 \mathrm{wh}$ & 4.620 & $265^{\circ} \mathrm{c}$ & $6539 \mathrm{wh}$ \\
\hline Rata-rata & 663,7 & $39,7^{\circ} \mathrm{c}$ & $970 \mathrm{wh}$ & 577.5 & $33,1^{\circ} \mathrm{c}$ & $817,3 \mathrm{wh}$ \\
\hline
\end{tabular}

Energi listrik yang di hasilkan

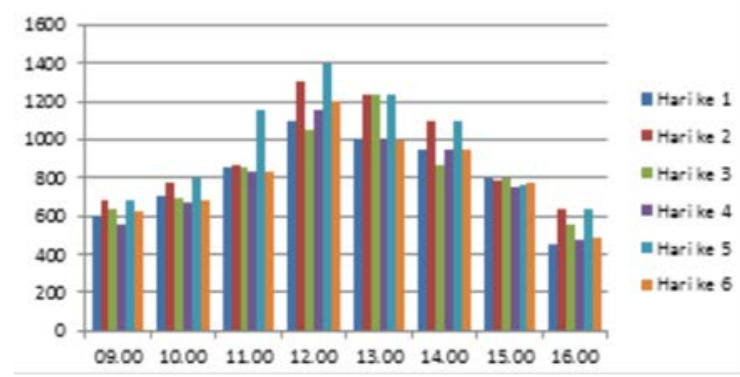

Gambar 9 .

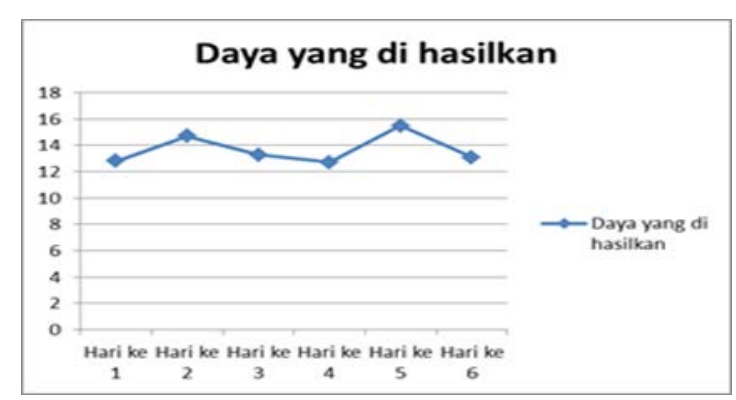

Gambar 10 .

Pemasangan yang bergerak mengikuti arah matahari hanya membutuhkan 16 pcs modul surya untuk Menghasilkan energi listrik yang nilainya sama

bahkan lebih dari pemasangan di atap yaitu 82,1 kwh dalam satu minggu.

\section{KESIMPULAN}

Maka dapat disimpukan bahwa :

1. PLTS on grid yang di pasang di atap gedung keluaran sel surya tidak maksimal di karenakan penyinaran tidak mengenai semua modul surya.

2. PLTS on grid yang mengikuti arah matahari dapat menghasilkan daya yang maksimal karena modul surya terkena penuh cahaya matahari dari pagi sampai sore.

3. Perbandingan investasi dari kedua sistem menghasilkan perbedaan yang signifikan karena investasi PLTS di atap gedung lebih tinggi cost nya di bandingkan PLTS mengikuti arah matahari.

\section{DAFTAR PUSTAKA}

[1] P. Manikandan, S. Karthick, S. Saravanan, and T. Divya, "Role of Solar Powered Automatic Traffic Light Controller for Energy Conservation,” International Research Journal of Engineering and Technology (IRJET), vol. 5, no. 12, pp. 989-992, 2018.

[2] D. A. Devi and A. Kumar, "Design and implementation of CPLD based solar power saving system for street lights and automatic traffic controller," International Journal of Scientific and Research Publications, vol. 2, no. 11, pp. 1-4, 2012.

[3] "Fotovoltaik," Wikipedia bahasa Indonesia, ensiklopedia bebas. Dec. 14, 2019, Accessed: Sep. 20, 2020. [Online]. Available: https://id.wikipedia.org/w/index.php?title=Fot ovoltaik\&oldid=16309290.

[4] O. Bishop, “Dasar-dasar elektronika,” Jakarta: Erlangga, 2004. 